\title{
Occurrence and control of genotoxins in drinking water: a monitoring proposal
}

\author{
Elisabetta Ceretti, ${ }^{1}$ Massimo Moretti, ${ }^{2}$ Ilaria Zerbini, ${ }^{1}$ Milena Villarini, ${ }^{2}$ Claudia Zani, ${ }^{1}$ \\ Silvano Monarca, ${ }^{2}$ Donatella Feretti ${ }^{1}$ \\ 'Department of Medical and Surgical Specialties, Radiological Sciences and Public Health, \\ University of Brescia; ${ }^{2}$ Department of Pharmaceutical Sciences (Unit of Public Health), University \\ of Perugia, Italy
}

\section{Significance for public health}

The provision of a safe drinking water is an important public health problem. Many studies have shown the presence of numerous genotoxins and carcinogens in drinking water. These toxic substances derive not only from pollution, but also from the disinfection treatments, particularly when water is obtained from surface sources and then chlorinated. The potential health risks of disinfection by-products (DBPs) from drinking water include cancer and adverse reproductive outcomes. People are exposed to disinfected drinking/shower/bathing water as a mixture of at least 600 identified DBPs and other toxic compounds via dermal, inhalation, and ingestion routes. Many of these substances are present in trace concentration, hardly detectable by chemical standard analysis. The monitoring of environmental genotoxins by short-term bioassays could allow a better evaluation of the global human exposure to water genotoxins and could help health officers and drinking water managers to reduce genotoxic hazards and distribute high quality drinking water.

\section{Abstract}

Many studies have shown the presence of numerous organic genotoxins and carcinogens in drinking water. These toxic substances derive not only from pollution, but also from the disinfection treatments, particularly when water is obtained from surface sources and then chlorinated. Most of the chlorinated compounds in drinking water are nonvolatile and are difficult to characterize. Thus, it has been proposed to study such complex mixtures using short-term genotoxicity tests predictive of carcinogenic activity. Mutagenicity of water before and after disinfection has mainly been studied by the Salmonella/microsome (Ames test); in vitro genotoxicity tests have also been performed in yeasts and mammalian cells; in situ monitoring of genotoxins has also been performed using complete organisms such as aquatic animals or plants (in vivo). The combination of bioassay data together with results of chemical analyses would give us a more firm basis for the assessment of human health risks related to the consumption of drinking water. Tests with different genetic end-points complement each other with regard to sensitivity toward environmental genotoxins and are useful in detecting low genotoxicity levels which are expected in drinking water samples.

\section{Introduction}

Many studies have shown the presence of numerous organic geno- toxins and carcinogens in drinking waters. These toxic substances derive not only from industrial, agricultural and urban pollution, but also from the disinfection treatments used for drinking water, particularly when water is obtained from surface sources and then chlorinated. In fact, even if the chlorination of drinking water has played a leading role in reducing mortality rates associated with waterborne pathogens, chemical analyses have found genotoxic/carcinogenic disinfection by-products (DBPs) in chlorinated surface water and epidemiological studies have highlighted some health hazards in populations using chlorinated drinking, thus giving rise to concern about potential health risks. ${ }^{1}$ The increased sensitivity of analytical techniques has enabled the detection of ever increasing numbers of DBPs. However, most of the organic compounds in drinking water are nonvolatile and are difficult to characterize. The difficulties encountered in performing chemical analyses, long-term carcinogenicity tests and epidemiological studies have encouraged the study of such complex mixtures using short-term genotoxicity tests, which are rapid, relatively cheap, and predictive of carcinogenic activity.

This paper is a partial review of the studies on the presence of genotoxins in drinking water and their potential human hazards. Finally, proposals for monitoring and controlling these micropollutants will be presented, in order to assist public health officers and water treatment managers in the production of high quality drinking water.

\section{The presence of genotoxins in the environment as complex mixtures}

It is well know that genotoxins are present in a variety of complex environmental matrices, including drinking water, surface water, aquatic sediment, soil, indoor air, and ambient urban air. In fact daily a number of chemicals are released into the environment from a variety of sources including stationary (e.g., industrial emissions, waste incinerators) or mobile (e.g., automobile exhaust) sources or, engineering procedures (e.g., chemical disinfection of drinking waters), and degradation processes (e.g., chemical transformation of applied pesticides through weathering).

This results in human exposures to complex multi-component chemical mixtures, present in the surrounding environmental media (water, air, soil), in food or in consumer products. Complex mixture was defined by U.S. Environmental Protection Agency ${ }^{2}$ as either i) simple mixtures, containing two or more identifiable components but few enough that the mixture toxicity can be adequately characterized by a combination of the components toxicities and the components interactions or ii) mixture containing so many components that any estimation of its toxicity based on its components' toxicities contains too much uncertainty and error to be useful. Among these, carcinogenic and 
mutagenic compounds are the most problematic in terms of toxicity estimation as they may exert a damage beyond that of individual and may be active through following generations.

The characterization and analysis of individual chemicals in complex mixtures performed to identify individual hazardous compounds provides almost incorrect information. However, with a few exceptions, chemical risk assessment considers the effects of single substances in isolation, an approach that is only justified if the exposure to mixtures does not bear the risk of an increased toxicity. This would be the case, for example, if only one chemical of the mixture is toxic while the others are biologically inert, or if empirical evidence showed that the joint action of chemicals is typically not larger than the effect of the most toxic compound. However this approach does not consider the importance of multiple chemical interactions, therefore it is impossible to predict the toxic and/or genotoxic properties of a complex mixture if synergistic, antagonistic or potentiating effects between the components occur. ${ }^{3}$ An alternative methodology to characterize the toxicity/genotoxicity of complex environmental samples are biological tests, which produce a global response to the complex mixture of chemicals without any prior knowledge of the mixture composition or its chemical properties, and therefore can detect the global human exposure and the synergistic activities of the pollutants. ${ }^{4} \mathrm{~A}$ conventional battery of test, such as bacterial mutagenicity assay (with Salmonella typhimurium or Escherichia coli strains), DNA damage (single cell-gel electrophoresis assay) and cytogenetic analysis (cytokinesis-block micronucleus assay) could be employed. Other novel approaches that may become available include proteomic, epigenomic and metabolomic profiles. $^{5}$

\section{Health hazards of drinking water genotoxins}

Epidemiological studies on health effects resulting from exposure to drinking water pollutants are not many and they are difficult to understand because of the lack of quantitative information on the concentration to which people have been exposed or on simultaneous exposure to other agents. A meta-analysis study has been conducted by Villanueva et al. ${ }^{6}$ on individual consumption of chlorinated drinking water and bladder cancer. The results indicated that long term consumption of chlorinated drinking water is associated with bladder cancer, particularly in men. The observed relative risk was only moderately high, but the population attributable risk could be important as the majority of the population of industrialised countries is potentially exposed to chlorination byproducts for long time periods.

Vinceti et al. ${ }^{7}$ investigated the mortality of a cohort of 5144 residents in Guastalla, northern Italy, who were supplied tap water with high trihalomethane content between 1965 and 1987 and showed a higher mortality from stomach, liver, lung, prostate and bladder cancer in males and from stomach, pancreas, breast and ovarian cancer and lymphocytic leukemia in females, detecting an association between trihalomethane exposure and increased cancer risk at some sites. However, the authors were unable to rule out the possibility of confounding due to smoking and other life-style factors.

Wang et al. ${ }^{8}$ have studied the cancer risk assessment from trihalomethanes in drinking water in Taiwan. The results revealed that the highest risk comes from the inhalation exposure to chloroform during showers, which also dominates the total risk associated with chloroform exposure.

Some epidemiological studies on the relationship between drinking water mutagenicity and cancer mortality have been carried out in Finland, where the results indicated a potential relationship between exposure to drinking water mutagenicity and the risk of lymphomas, pancreatic cancer, and bladder, rectal, kidney and stomach cancers. ${ }^{9}$

\section{The detection of genotoxins in drinking water by chemical analyses: the case of the disinfec- tion by-products}

The discovery in 1974 by Rook of the formation of new toxic substances after chlorination of a Dutch surface water changed deeply the water treatment techniques. The trihalomethanes (THMs) are the most prevalent class DBPs identified and include chloroform, bromodichloromethane, dibromochloromethane, and bromoform. ${ }^{10}$ Many of these disinfection by-products (DBPs) have shown to be potentially harmful to human and aquatic organisms.

It has been found that chlorine reacts with the natural organic matters (NOM), anthropogenic contaminants and bromide/iodide in raw water leading to the formation of a wide variety of toxic DBPs:

\section{$\mathrm{NOM}+\mathrm{Br}+\mathrm{I}+\mathrm{HOCl} \rightarrow$ chlorinated, brominated, iodinated, and mixed bromo-chloro DBPs}

The most critical variables that affect the formation of DBPs are related to source water qualities, water treatment choices, and distribution system characteristics. The source water characteristics is very important and the DBP formation is influenced by NOM parameters, the season, temperature, $\mathrm{pH}$ and the presence of bromide, iodide or algal-derived organic matter. ${ }^{11}$

Analysis of bulk NOM parameters, such as total organic carbon (TOC) or dissolved organic carbon (DOC) and $\mathrm{UV}_{254}$ absorbance, can provide some indication on its potential to form DBPs.

Other factors affecting the formation of DBPs are the disinfectant used (e.g., chlorine, chloramine, ozone, chlorine dioxide), the introduction of chemicals that react with disinfectant (e.g., polymers, such as polyamine used during the coagulation process), other water treatments (e.g., lime softening), the time and the reaction conditions provided. DBPs can be formed also during water distribution in the pipelines as a result of chemical reaction with organic matters, or microbiological action. ${ }^{11}$

The increased sensitivity of analytical techniques has enabled the detection of over 600 DBPs: e.g., the haloacetic acids (HAAs), the haloacetonitriles (HANs), iodo-THMs (i-THMs), halonitromethanes (HNMs), haloaldehydes (HAs), haloketones (HKs), and nitrosamines some of them genotoxic and potentially carcinogenic for humans. Chloroform is the most abundant THM and was the first DBP to be identified as a carcinogen in animals. Other DBPs reported to be carcinogenic in animal studies include the brominated trihalomethanes, haloacetonitriles, bromate, haloacetic acids, nitrosamines and MX, one of the most potent direct-acting mutagens in Ames test and responsible for a significant portion of the mutagenicity detected in chlorine-disinfected drinking water. ${ }^{12}$

In general, brominated DBPs are both more genotoxic and carcinogenic than their chlorinated analogs, with recent findings indicating that iodinated DBPs are more toxic (i.e., genotoxic/carcinogenic) than chlorinated/brominated compounds. Wagner et al. ${ }^{13}$ have recently studied five nitrosamine DBPs for genotoxicity and found that three were both mutagenic in Salmonella typhimurium and genotoxic in CHO cells ( $N$-nitrosodimethylamine, $N$-nitrosopiperidine, $N$-nitrosomorpholine).

But also the distribution system may contribute a DBPs formation. Chlorinated by-products of polycyclic aromatic hydrocarbons (PAH) known genotoxic/carcinogenic compounds were formed in distributed drinking water and in the pipe coatings. ${ }^{14}$

However, only a small number of DBPs has been quantified and evaluated for their genotoxic or mutagenic potential, as well as for their possible adverse health effects.

Epidemiological studies provide further evidence that exposure to 
increased levels of DBPs may be associated with adverse developmental effects. Mothers exposed to water with increased trihalomethane concentrations have been shown to be at greater risk for a variety of pregnancy related complications including birth defects, stillbirths, spontaneous abortions, and fetal growth retardation. ${ }^{15}$

\section{The detection of genotoxins in drinking water by short-term bioassays}

Most of the organic compounds in drinking water, including genotoxic ones, are known to be nonvolatile and are difficult to characterize. The difficulties encountered in performing chemical analyses, longterm carcinogenicity tests and epidemiological studies have encouraged the study of such complex mixtures using short-term mutagenicity tests, which are predictive of carcinogenic activity. But no single short-term test can predict mutagenicity/carcinogenicity of a compound or a mixture. Therefore batteries of these short-term tests have to be performed to evaluate the mutagenic potential of drinking water.

Moreover, the application of mutagenicity tests on water concentrates allows researchers to study the combined action of complex mixtures of water disinfection by-products and to obtain data better correlated with actual human exposure. Therefore, it appears to be particularly important for preventive purposes to analyse the mutagenic activity of the nonvolatile fraction of drinking water using short-term mutagenicity tests. The potential mutagenicity of concentrates of drinking water samples before and after disinfection has mainly been studied by means of the Salmonella/microsome test (Ames test), the most widely validated mutagenicity test, included in the Standard Methods for Examination of Water and Wastewater in 1998 as official mutagenicity test for aquatic environment. ${ }^{16}$

Most of the bacterial mutagenicity of chlorinated surface water samples is probably due to chlorination of NOM, and in particular to the presence of chlorinated furanones. There are also some applications with positive results using other in vitro bioassays performed in yeasts, mammalian cells and human lymphocytes. Studies on the mutagenicity of water treated with alternative disinfectants, such as ozone, chlorine dioxide and chloramines, are less numerous. Short-term mutagenicity tests have also been used for evaluating the removal of water mutagens by adsorption on granular activated carbon (GAC) and the potential genotoxicity of coal tar pitch paints used against corrosion of iron pipelines. ${ }^{17,18}$

Direct detection of the genetic effects with in vivo tests, using complete organisms such as aquatic animals (fish, mollusks) or plants (Vicia faba, Allium cepa and Tradescantia spp.) has also been performed for monitoring in situ the presence of mutagens in aquatic environments and also in drinking water. ${ }^{19-21}$

Some of these studies, in particular, were integrated multicentre studies conducted to study the different potential formation of genotoxic DBPs by known water disinfectants (hypochlorite and chlorine dioxide) and a new water disinfectant (peracetic acid) and to evaluate the potential formation of genotoxins in distributed drinking water. These studies have been carried out using a battery of different short-term genotoxicity tests together with standard chemical analyses.

The first multicentre study was carried out using a battery of in vivo and in vitro short-term tests revealing different genetic end-points in order to study lake water genotoxicity after disinfection with different biocides ( $\mathrm{NaClO}, \mathrm{ClO}_{2}$ and peracetic acid), in different seasons. In particular, the in vivo tests performed directly by exposing animal and vegetal bio-indicators to waters were as follows: micronuclei test in Tradescantia pollen; chromosomal aberration test in root cells of Allium cepa; micronuclei test in root cells of Vicia faba; micronuclei test in erythrocytes of fish or haemocytes of molluscs; DNA damage test (comet test) in fish cells; assays for enzymatic modifications in fish tissues. ${ }^{21}$ The in vitro tests performed on the water samples concentrated by solid phase extraction on silica $\mathrm{C} 18$ were: Ames test; mutagenicity test (Mutatox) with bioluminescent bacteria (Vibrio fisheri); SOS Chromotest with Escherichia coli; tests with Saccharomyces cerevisiae; micronuclei and chromosomal aberrations in human lymphocytes; comet test on human leukocytes; enzymatic activity tests on human hepatic cells and trout hepatocytes. The concentrates were also undergone to chemical analyses to detect by-products.

The results of the research showed that some tests were more sensitive than others, and were applied successfully in the study of disinfected lake waters. Moreover, $\mathrm{NaClO}$ and $\mathrm{ClO}_{2}$ increased in vitro water genotoxicity, whereas peracetic acid was able to slightly reduce raw water activity. Also the in vivo tests with plant, fish and shellfish showed that peracetic acid disinfection produced lower genotoxicity. ${ }^{20-}$

The second multicentre study have integrated chemical analytical and biological approach to detect the presence of genotoxins in distributed drinking water of four Italian cities which obtain their water supply from different sources (surface or deep waters). A battery of rapid in vitro tests (Microtox test, Ames test on Salmonella typhimurium, Saccaromyces cerevisiae test, SOS Chromotest on Escherichia coli, comet test on human leukocytes and HepG2 cell line, micronuclei in HepG2 cells) and in vivo tests (comet and micronuclei tests in fish cells, assays for enzymatic modifications, and test on plant cells as Tradescantia/MN, Allium cepa and Vicia faba tests) was utilized for study the potential genotoxicity of drinking water before and after distribution in pipelines. ${ }^{24}$

In vitro and in vivo tests evidenced an increased genotoxicity in distributed water in both surface and deep water supplies, showing the important role of distribution system on the water quality. Among the assays with plants the Allium cepa test was the most sensitive showing mutagenicity in disinfected distributed and raw water samples. ${ }^{25,26}$

\section{Methods for controlling and removing precur- sors and genotoxins in disinfected drinking water}

The most common approach in DBP control strategy, useful also in drinking water genotoxicity control, is the reduction in the levels of precursor material (NOM, $\mathrm{Br}^{-}, \mathrm{I}^{-}$, etc.) reacting with chlorine. The main treatment processes are coagulation, anion exchange, membranes, activated carbon (AC), biotreatment, advanced oxidation processes (AOPs), and ozone. ${ }^{27}$

Another effective method to control chlorinated DBPs in drinking water is the use of alternative disinfectants - ozone, chloramines, chlorine dioxide and ultraviolet (UV) light - alone or in combination with chlorine. The use of various disinfectant alternatives to chlorination must be considered with caution, however, because they may form toxic non-chlorinated DBPs more cytotoxic and genotoxic than THMs and HAAs. For disinfection with chlorine dioxide $\left(\mathrm{ClO}_{2}\right)$, there is no evidence of reactions with humic acids to form trihalomethanes. However, the inorganic DBPs such as chlorite and chlorate are formed and they also have human health risk implications ${ }^{28}$, and have shown to be genotoxic in plants. ${ }^{29}$

In ozonation, the most important by-product formed depends on the presence of bromide, the bromated, a carcinogen that induces oxidative damage to DNA and has been considered to likely have a genotoxic mode of action. ${ }^{30}$

The effectiveness of innovative drinking-water treatments designed to remove toxic and mutagenic organic micropollutants from lake 
waters used for human consumption was evaluated. ${ }^{31}$ The adsorption on granular activated carbon (GAC) filter technique was compared with the more innovative resin column techniques (XAD-4 and Ambersorb563 ) and with the advanced oxidation processes (AOPs) with $\mathrm{UV} / \mathrm{O}_{3}$ and $\mathrm{UV} / \mathrm{O}_{3} / \mathrm{H}_{2} \mathrm{O}_{2}$. The results found a decrease of the mutagenic and toxic activities of the lake water after adsorption on GAC and resins, while the AOP process generally increased these parameters. ${ }^{32}$

\section{Proposals for a monitoring program of drinking water genotoxins}

People are exposed to disinfected drinking/shower/bathing water as a mixture of at least 600 identified DBPs and other toxic compounds via dermal, inhalation, and ingestion routes.

Despite the rapid development of environmental chemistry analysis methods such as modern mass spectrometry analyses, it remains difficult to identify every water pollutants because of limitations in analytical capacity, cost, and time. Many environmental chemicals are pres- ent in trace concentration or are nonvolatile and therefore are not readily identified.

The combination of bioassay data together with results of chemical analyses would give us a more firm basis for the assessment of human health risks related to the consumption of drinking water. We assume that a battery of genotoxicity tests should be used. Tests with different genetic end-points complement each other with regard to sensitivity toward environmental genotoxins and are useful in detecting low genotoxicity levels which are expected in drinking water samples. The majority of publications on genotoxic effects of water samples refers to only one test system and almost all data come from the Ames test.

Therefore, the combination of genotoxicity/mutagenicity tests could be useful to deduce the genotoxic potential of contaminants in drinking water more relevantly. The flow chart shown in Figure 1 illustrates a proposal of an integrated chemical/biotoxicological approach for monitoring drinking water genotoxins, to be carried out especially when new source, treatment or distribution processes are introduced in a water plant. We propose to analyze both un-concentrated and concentrated water samples before and after treatment and distribution and to employ in parallel standard chemical analyses and at least four mutagenicity/genotoxicity short-term bioassays tests (i.e.,

Table 1. Strengths and weaknesses of short-term genotoxicity tests.

\begin{tabular}{|c|c|c|}
\hline Bioassay/Genetic end-point & $\begin{array}{l}\text { Strengths /Advantages } \\
\qquad \text { Salmonella/microsomes test }\end{array}$ & Weaknesses /Disadvantages \\
\hline $\begin{array}{l}\text { Point mutations (base-pair substitution } \\
\text { and frameshift mutations). }\end{array}$ & $\begin{array}{l}\text { Sensitivity to environmental mutagens; } \\
\text { Predictive of carcinogenicity; } \\
\text { Standardized procedure available in the literature; } \\
\text { Simple and inexpensive. }\end{array}$ & $\begin{array}{l}\text { Test based on prokaryotic cells; Inability to detect some } \\
\text { mutagenic compounds which may be active in mammalian cells } \\
\text { after metabolic activation (detection of promutagens by adding } \\
\text { S9 fraction); Inability to detect some carcinogenic compounds } \\
\text { which do not possess mutagenic capabilities } \\
\text { (heavy metals, asbestos, etc.); } \\
\text { The test requires a preliminary long and laborious preparation } \\
\text { of water samples; Time-consuming. }\end{array}$ \\
\hline
\end{tabular}

DNA damages as chromosome aberrations and disturbances in the mitotic cycle.

The test provides information to evaluate action mechanisms (clastogenic and/or aneugenic effects).
Excellent genetic model to detect environmental mutagens; It provides cytotoxicity information; Allow the use of samples "as such" (do not require previous preparation of water samples); Use in situ; Inexpensive; Easily handled.
High variability in sensitivity of organisms;

Not always a linear dose-response to increasing concentrations of pollutants is evident; Deficiency of applied studies / Lack of standardized methods; The analysis of the slide is time-consuming and each sample require a large number of cells to be counted; Microscope analysis is operator dependent.
Primary DNA damage as single- and/or double- strand breaks, excision repair sites, alkali labile sites, cross links
Applicable on many eukaryotic cell types; In vitro, a cultivation step is not required; Possible estimation of global repair capacity; The test also gives some information on the induction of apoptosis; A small number of cells per sample is needed for the test; Highly sensitive in detecting primary DNA; Collection of data at the level of individual cells allows robust statistical analyses; Using lesion-specific enzymes in the assay, its range and sensitivity are greatly increased; Inexpensive; Fast and simple
The detected DNA damage does not correspond to fixed mutations; Need of internal reference to avoid experimental variation during the electrophoresis

\section{Micronucleus test}

Chromosome aberrations and genome mutation; Biomarker of early effect (relevant for risk assessment of cancer); Provides information to evaluate action mechanisms (clastogenic and/or aneugenic effects)
Applicable on many cell types; Some cells types can easily be obtained also from human (lymphocytes, oral mucosa cells, hear root, skin fibroblast, sperms);

The background level and spontaneus variability is low enough in some cells to allow for a reasonable statistical testing; Assessment of cell proliferation (binucleated cells); Assessment of genic amplification (buds); Rapid and simple to carry out; Inexpensive (requires standard equipment usually available in every cytological laboratory)
The assay is proliferation-dependent; requires cell division for expression of MN; The origin of micronuclei is heterogeneous; The spontaneous frequency of micronuclei is comparatively high and rather variable in some cells; Not always a linear dose-response to increasing concentrations of pollutants is evident; Does not detect point mutations; Does not detect all structural chromosome aberrations 


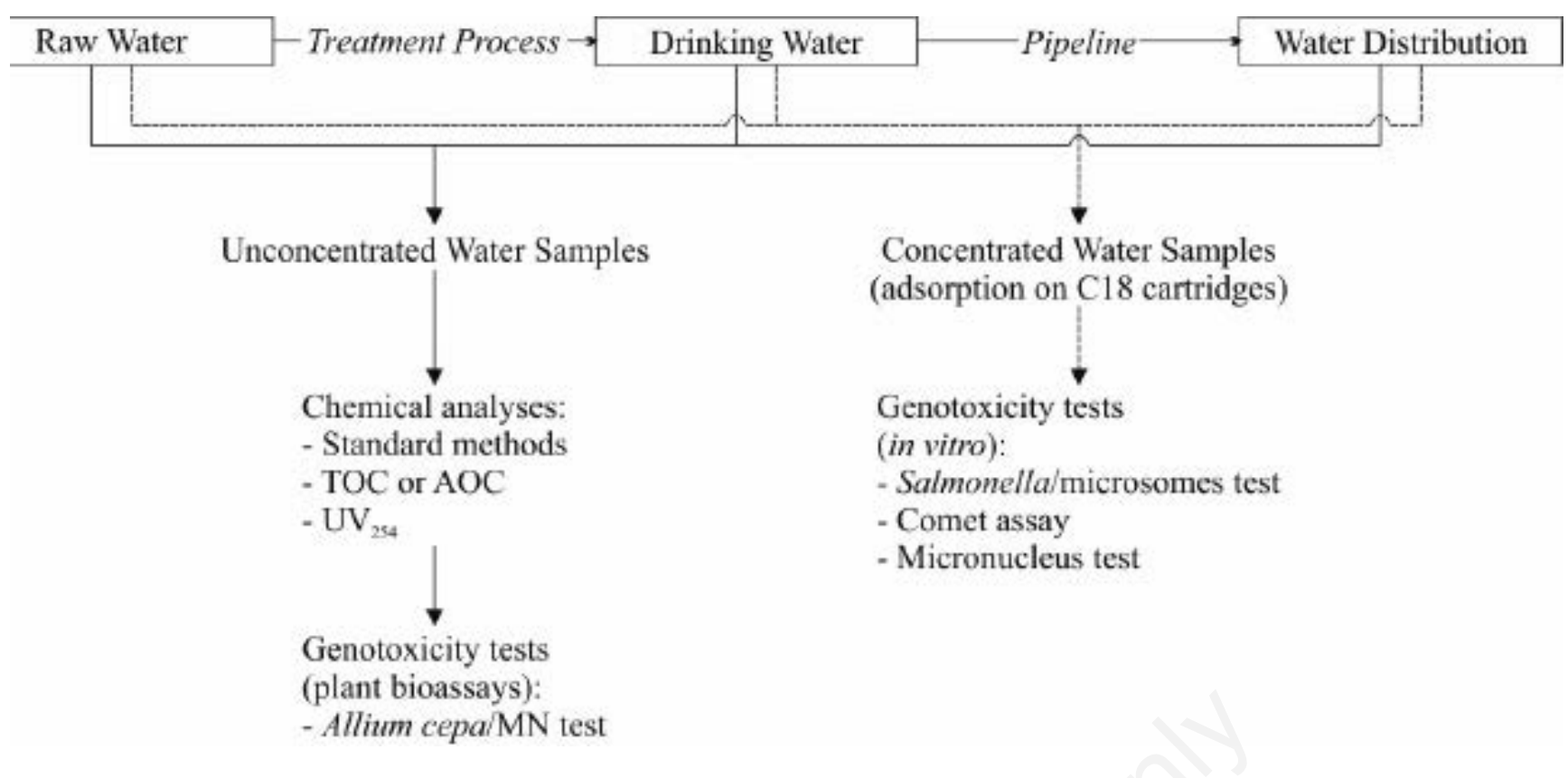

Figure 1. Flow chart of a proposal program for monitoring genotoxins in drinking water.

Salmonella/microsomes test, Allium cepa/MN test, comet assay and micronucleus test in human cell lines), following a previous published approach. $^{21}$

Table 1 summarizes strengths and weaknesses of short-term genotoxicity tests proposed for the detection of genotoxic pollutans in drinking water. As each bioassay has particular strengths and weaknesses, in an integrated research strategy combining chemical/biotoxicological approaches for the evaluation of complex mixtures of DBPs formed during chemical disinfection of water, different genotoxicity tests having different genetic end-points should be considered. ${ }^{32}$

The monitoring of environmental genotoxins by short-term bioassays could allow a better evaluation of the global human exposure to water genotoxins and could help health officers and drinking water managers to reduce genotoxic hazards and distribute high quality drinking water.

Correspondence: Milena Villarini, Department of Pharmaceutical Sciences (Unit of Public Health), University of Perugia, Via del Giochetto, 06122 Perugia, Italy.

Tel.: +39.075.5857417 - Fax +390755857428.

E-mail: milena.villarini@unipg.it

Key words: Drinking water genotoxins, disinfection by-products, short-term genotoxicity tests, health effects, control of drinking water genotoxins.

Contributions: the authors contributed equally.

Conflict of interest: the authors declare no potential conflict of interest.

Received for publication: 29 November 2016.

Accepted for publication: 10 December 2016.

(C) Copyright E. Ceretti et al., 2016

Licensee PAGEPress, Italy

Journal of Public Health Research 2016;5:769

doi:10.4081/jphr.2016.769

This work is licensed under a Creative Commons Attribution NonCommercial 4.0 License (CC BY-NC 4.0).

\section{References}

1. Morris RD. Drinking water and cancer. Environ Health Perspect 1995;103:225-31.

2. EPA. US. Supplementary Guidance for Conducting Health Risk Assessment of Chemical Mixtures. 630/R-00/002 E, editor. Washington, DC: US: Environmental Protection Agency, Risk Assessment Forum; 2000.

3. Groten JP, Feron VJ, Suhnel J. Toxicology of simple and complex mixtures. Trends Pharmacol Sci 2001;22:316-22.

4. Zegura B, Heath E, Cernosa A, Filipic M. Combination of in vitro bioassays for the determination of cytotoxic and genotoxic potential of wastewater, surface water and drinking water samples. Chemosphere 2009;75:1453-60.

5. Martin FL. Complex mixtures that may contain mutagenic and/or genotoxic components: a need to assess in vivo target-site effect(s) associated with in vitro-positive(s). Chemosphere 2007;69:841-8.

6. Villanueva CM, Fernandez F, Malats N, et al. Meta-analysis of studies on individual consumption of chlorinated drinking water and bladder cancer. J Epidemiol Community Health 2003;57:166-73.

7. Vinceti M, Fantuzzi G, Monici L, et al. A retrospective cohort study of trihalomethane exposure through drinking water and cancer mortality in northern Italy. Sci Total Environ 2004;330:47-53.

8. Wang GS, Deng YC, Lin TF. Cancer risk assessment from trihalomethanes in drinking water. Sci Total Environ 2007;387:86-95.

9. Koivusalo M, Vartiainen T, Hakulinen T, et al. Drinking water mutagenicity and leukemia, lymphomas, and cancers of the liver, pancreas, and soft tissue. Arch Environ Health 1995;50:269-76.

10. Rook JJ. Formation of haloforms during chlorination of natural waters. Wat Treat Exam 1974;23:7.

11. Bull RJ, Rice G, Teuschler LK. Determinants of whether or not mixtures of disinfection by-products are similar. J Toxicol Environ Health A 2009;72:437-60.

12. Richardson SD, Plewa MJ, Wagner ED, et al. Occurrence, genotox- 
icity, and carcinogenicity of regulated and emerging disinfection by-products in drinking water: a review and roadmap for research. Mutat Res 2007;636:178-242.

13. Wagner ED, Hsu KM, Lagunas A, Mitch WA, Plewa MJ. Comparative genotoxicity of nitrosamine drinking water disinfection byproducts in Salmonella and mammalian cells. Mutat Res 2012;741:109-15.

14. Tillner J, Hollard C, Bach C, et al. Simultaneous determination of polycyclic aromatic hydrocarbons and their chlorination by-products in drinking water and the coatings of water pipes by automated solid-phase microextraction followed by gas chromatographymass spectrometry. J Chromatogr A 2013;1315:36-46.

15. Legay C, Rodriguez MJ, Serodes JB, Levallois P. Estimation of chlorination by-products presence in drinking water in epidemiological studies on adverse reproductive outcomes: a review. Sci Total Environ 2010;408:456-72.

16. APHA. Standard Methods for the Examination of Water and Wastewater. 20th ed: American Public Health Association; 1998.

17. Monarca S, Meier JR, Bull RJ. Removal of mutagens from drinking water by granular activated carbon: evaluation using bacterial mutagenicity tests. Water Res 1983;17:11.

18. Monarca S, Meier JR. Mutagenicity of coal tar paints used in drinking water distribution systems. Sci Total Environ 1984;39:251-63.

19. Helma C, Sommer R, Schulte-Hermann R, Knasmüller S. Enhanced clastogenicity of contaminated groundwater following UV irradiation detected by the Tradescantia micronucleus assay. Mutat Res 1994;323:93-8.

20. Monarca S, Rizzoni M, Gustavino B, et al. Genotoxicity of surface water treated with different disinfectants using in situ plant tests. Environ Mol Mutagen 2003;41:353-9.

21. Monarca S, Zani C, Richardson SD, et al. A new approach to evaluating the toxicity and genotoxicity of disinfected drinking water. Water Res 2004;38:3809-19.
22. Guzzella L, Monarca S, Zani C, et al. In vitro potential genotoxic effects of surface drinking water treated with chlorine and alternative disinfectants. Mutat Res 2004;564:179-93.

23. Monarca S, Feretti D, Zani C, et al. Genotoxicity of drinking water disinfectants in plant bioassays. Environ Mol Mutagen 2005;46:96103.

24. Feretti D, Zani C, Zerbini I, et al. A study to detect the presence of genotoxins in the drinking water distribution systems of four Italian cities. Ig Sanità Pubbl. 2008;64:415-30.

25. Zani C, Feretti D, Buschini A, et al. Toxicity and genotoxicity of surface water before and after various potabilization steps. Mutat Res 2005;587:26-37.

26. Guzzella L, Di Caterino F, Monarca S, et al. Detection of mutagens in water-distribution systems after disinfection. Mutat Res 2006;608:72-81.

27. Parsons SA, Goslan EH, McGrath S, et al. Disinfection Byproduct Control. In: Ahuja S, ed. Comprehensive Water Quality and Purification. Waltham: Elsevier; 2014. pp 120-47.

28. WHO. Chlorite and chlorate in drinking-water. Background document for development of WHO Guidelines for Drinking-water Quality. World Health Organization, 2005.

29. Feretti D, Zerbini I, Ceretti E, et al. Evaluation of chlorite and chlorate genotoxicity using plant bioassays and in vitro DNA damage tests. Water Res 2008;42:4075-82.

30. Moore MM, Chen T. Mutagenicity of bromate: implications for cancer risk assessment. Toxicology 2006;221:190-6.

31. Guzzella L, Feretti D, Monarca S. Advanced oxidation and adsorption technologies for organic micropollutant removal from lake water used as drinking-water supply. Water Res 2002;36:4307-18.

32. Gatehouse D. Short-Term Testing for Genotoxicity. In: Alison MR, ed. The Cancer Handbook (2nd edition): John Wiley and Sons; 2007. 